\title{
An autopsy review of five hundred and sixty nine non-traumatic brought in dead patients in Lagos, Nigeria
}

\author{
Francis Adedayo Faduyile ${ }^{1 *}$, Sunday Sokunle Soyemi ${ }^{1}$, Daniel Ayodele Sanni ${ }^{2}$, Festus Edobor Emiogun ${ }^{1}$, \\ Fadesewa Ibiolagbajosi Osuolale ${ }^{1}$ and Kikelomo Ololade Wright ${ }^{3}$
}

\begin{abstract}
Background: There are many cases that present to the emergency room as brought in dead (BID) and in such cases, previous medical history of the deceased is unknown. Many of the medical problems are either preventable or treatable if managed on time. This study is aimed to determine the age, gender and causes of BID.

Results: This is a 6 year retrospective autopsy study of all BID patients in Lagos State University Teaching Hospital, Ikeja between 1st January 2010 and 31st December 2015. The data were retrieved from the autopsy reports and were analysed using Statistical Package for Social Sciences version 18. Test for statistical significance was set as $p<0.05$. There were $1016 \mathrm{BID}$ recorded representing $9.3 \%$ of all deaths during the period under study. A total of 569 cases of BID that were analysed in this study after excluding hypertension related deaths. The male to female ratio was 1.37:1. The 4th decade was the predominant age group (22.7\%). Cardiovascular (25.5\%), Asphyxia related (23.0\%), Gastrointestinal tract [GIT] (16.5\%) and respiratory (15.1\%) were the common system seen.

Thromboembolism and haemorrhage, drowning, severe dehydration and tuberculosis were the most common causes of cardiovascular, asphyxia, GIT and respiratory system deaths respectively.

Conclusions: Cardiovascular system related death was the most common cause of BID with thromboembolism and haemorrhage as major secondary causes. Tuberculosis was the commonest cause of respiratory system death. BIDs are seen more in male than the female gender. There is need for the government to increase the awareness and health seeking behaviour among the populace.
\end{abstract}

Keywords: Asphyxia, Tuberculosis, Drowning, Severe dehydration, BID

\section{Background}

The World Health Organization (WHO) already recognizes sudden death as a significant health problem and defines it as death occurring less than $24 \mathrm{~h}$ from the onset of sudden changes in previous clinical conditions (Akinwusi et al. 2013; Gülmen and Meral 2009). It is classified as non-traumatic deaths (Akinwusi et al. 2013).

There are however many cases that present to the emergency room as brought in dead (BID). In such cases, previous medical history of the deceased is

\footnotetext{
* Correspondence: abaaye@yahoo.com

${ }^{1}$ Department of Pathology and Forensic Medicine, Lagos State University

Teaching Hospital, Ikeja, Lagos, Nigeria

Full list of author information is available at the end of the article
}

unknown and many times the attending physician just certifies the body dead with no further clerking.

Jafarery and Korejo in their study on mothers who were brought - in- dead showed that the causes of delay were economic, socio-cultural factors and inadequate maternal services (Jafarery and Korejo 1995). They concluded that the medical problems were either preventable or treatable if managed in time and that a combination of economic, social and cultural factors played a more significant role in these deaths than medical causes (Jafarery and Korejo 1995). Some Nigerian studies also found out, amongst other causes, that the poverty state of most patients, late presentation at the point of care, ignorance and the interference by untrained persons claiming to give medical care, often 
lead to most avoidable death at the emergency department (Adesunkanmi et al. 2002; Ekere et al. 2005).

The Lagos State Coroner's system law however made it mandatory for all (BID) deaths where the cause is unknown by the attending physician to have an autopsy done. This is to determine the cause of death and in some cases the manner of death for possible prosecution (Lagos State Coroners law 2007).

This study is to determine the age and gender pattern of BID as well as the cause of sudden, unexpected deaths (SUND) which we believe will help in the prevention and early management of the critically ill patients who presented early in the emergency department of the hospital.

\section{Materials and methods}

This is a 6 year retrospective autopsy study of all brought in dead (BID) patients to our hospital, Lagos State University Teaching Hospital, Ikeja between 1st January 2010 and 31st December 2015. All cases of BID and found dead patients were sent to the Department of the Pathology and Forensic Medicine of the Lagos State University Teaching Hospital for autopsy being a coroner's case in line with the Lagos State Coroner's law of 2007 [6]. All BID and found dead were admitted for the mortuary through the emergency room; and there are usually scanty clerking done in the emergency room.

The data were retrieved from the autopsy reports which included the demographic profile as well as the autopsy findings. BID as a result of traumatic deaths and the 447 BID patients that autopsy confirmed Hypertensive Heart disease (HHD) as the cause of death were excluded from the study. Deaths from HHD were excluded because of their numbers and the need to exhaustively discuss them fully in another paper. The primary cause of death was classified under the organ and system affected namely Central Nervous System (CNS), Cardiovascular system (CVS), Gastro intestinal tract (GIT), Asphyxia, Respiratory system, cancer and others. The data retrieved were analysed using IBM Statistical Package for Social Sciences version 18 . The data were presented in tables, percentages and bar chart. Test for statistical significance was done using Chi square and $p<0.05$ was considered as statistical significant.

The limitation of this study being a retrospective study is our inability of getting parameters such as occupation, time of death, manner of death, place of occurrence because they were not in the case notes and autopsy records. Also because most brought in dead do not have provisional diagnosis and the previous medical records of the deceased are usually not available it was therefore difficult to have provisional diagnosis to compare with our autopsy causes of death and we could not provide concise information on the state of litigation among the cases.

\section{Results}

There were 1016 BID recorded during the period under study out of the 11,042 deaths representing $9.3 \%$ of all certified deaths in the hospital. With the exclusion of the 447 BID cases due to Hypertensive heart disease as well as the traumatic deaths, we had a total of 569 cases of BID that were analysed for this study. This represents $56 \%$ of the BID cases during the period under study. The male to female ratio was 1.37:1. The 4th decade was the most predominant age group seen with $22.7 \%$ while the 1st decade recorded the lowest cases (3.0\%) Table 1.

The male predominates all through the age groups except the 3rd decade where the female predominated. The 3rd and 4th decades are the active child bearing age in the female and had the highest presentation in the female gender. There was however no significant relationship between the gender and the age (Table 1).

Table 2 showed that most death was as a result of cardiovascular system related causes which was followed by asphyxia related causes. Central Nervous system related causes however showed the least overall cause of death in all age groups.

Table 3 shows drowning as the most common cause of asphyxia deaths and was followed by aspiration of gastric content. Carbon monoxide poisoning was the cause of death in some of the burns with inhalation injury.

Respiratory infections were the most common cause of respiratory related BID deaths with pulmonary tuberculosis which accounted for $48.8 \%$ followed by lobar pneumonia $37.2 \%$ Table 3.

Severe dehydration accounted for most causes of GIT related deaths as a result of majorly enterocolitis or gastroenteritis and this was followed by Peritonitis from perforated gastric ulcers and perforated intestine Table 4 .

Thromboembolism and obstetrics haemorrhage were the most common causes of cardiovascular deaths, this was followed by ischemic heart disease following coronary artery thrombosis. Post surgical haemorrhage were

Table 1 Demographic profile

\begin{tabular}{llll}
\hline \multirow{2}{*}{ Age (years) } & \multicolumn{2}{l}{ Gender (\%) } & \multirow{2}{*}{ Total } \\
\cline { 2 - 3 } & Male & Female & \\
\hline $0-10$ & $12(3.6 \%)$ & $5(2.1 \%)$ & $17(3.0 \%)$ \\
$11-20$ & $13(4.0 \%)$ & $10(4.2 \%)$ & $23(4.0 \%)$ \\
$21-30$ & $49(14.9 \%)$ & $51(21.3 \%)$ & $100(17.6 \%)$ \\
$31-40$ & $67(20.4 \%)$ & $62(25.8 \%)$ & $129(22.7 \%)$ \\
$41-50$ & $54(16.4 \%)$ & $35(14.6 \%)$ & $89(15.6 \%)$ \\
$51-60$ & $70(21.3 \%)$ & $29(12.1 \%)$ & $99(17.4 \%)$ \\
$61-70$ & $40(12.2 \%)$ & $24(10.0 \%)$ & $64(11.2 \%)$ \\
Above 70 & $24(7.3 \%)$ & $24(10.0 \%)$ & $48(8.4 \%)$ \\
Total & $329(100.0 \%)$ & $240(100.0 \%)$ & $569(100.0 \%)$ \\
\hline P=0.01 & & &
\end{tabular}

$P=0.191$ 
Table 2 Table showing the causes of death in relation to organ system

\begin{tabular}{lll}
\hline Cause & Frequency & Percentage (\%) \\
\hline CNS & 18 & 3.2 \\
CVS & 145 & 25.5 \\
GIT & 94 & 16.5 \\
Septicaemia & 31 & 5.4 \\
Asphyxia & 131 & 23.0 \\
Respiratory & 86 & 15.1 \\
Cancer & 62 & 10.9 \\
Others & 2 & 0.4 \\
Total & 569 & 100.0 \\
\hline
\end{tabular}

those that died while being referred to our centre from other hospitals following surgeries Table 4.

Figure 1 shows that most death occurred in the 2160 years age group. Cancer related deaths were very few in the younger age group which also showed no CVS and Septicaemia related deaths. Cardiovascular system related deaths with haemorrhage as the most common cause was majorly seen in the 21-60 years age group which coincided with the reproductive age group of women.

Table 3 Asphyxia and respiratory causes of BID

\begin{tabular}{lll}
\hline & Frequency & Percentage \\
\hline Asphyxia & 10 & 7.6 \\
Burn/Inhalational Injury & 9 & 6.9 \\
Eclampsia & 13 & 9.9 \\
Strangulation & 8 & 6.1 \\
Hanging & 30 & 22.9 \\
Drowning & 10 & 7.6 \\
Obstructive Airways & 13 & 9.9 \\
Bronchial Asthma & 4 & 3.1 \\
Pulmonary Oedema & 2 & 1.5 \\
Seizure Disorder & 6 & 4.6 \\
Drug Overdose & 5 & 3.8 \\
Foreign Body Aspiration & 3 & 2.3 \\
Ingestion of Chemical & 18 & 13.8 \\
Aspiration of Gastric Content & 131 & 100.0 \\
Total & & \\
Respiratory & 32 & 37.2 \\
Lobar Pneumonia & 9 & 10.5 \\
Bronchopneumonia & 42 & 48.8 \\
Pulmonary Tuberculosis & 3 & 100.0 \\
Pulmonary Oedema & & \\
Total & &
\end{tabular}

Table 4 Gastrointestinal tract and cardiovascular causes

\begin{tabular}{lll}
\hline & Frequency & Percentage \\
\hline Gastrointestinal Tract & 33 & 35.1 \\
Enterocolitis & 10 & 10.6 \\
Intestinal Obstruction & 3 & 3.2 \\
Hepatitis & 18 & 19.1 \\
Gastroenteritis & 5 & 5.3 \\
Duodenal Ulcer & 19 & 20.2 \\
Perforated Gastric Ulcer & 6 & 6.4 \\
Typhoid Enteritis & 94 & 100.0 \\
Total & & \\
Cardiovascular causes & 6 & 4.1 \\
Valvular heart failure & 1 & 0.7 \\
Senile myocardial degeneration & 33 & 22.8 \\
Thromboembolism & 30 & 20.7 \\
Coronary artery thrombosis & 33 & 22.8 \\
Obstetrics haemorrhage & 10 & 6.9 \\
Post surgery haemorrhage & 5 & 3.4 \\
Bleeding Gastric Ulcer & 3 & 2.1 \\
Ruptured Oesophageal varices & 24 & 16.5 \\
Electrocution & 145 & 100 \\
Total & &
\end{tabular}

\section{Discussion}

The age range of patients seen in this study was between 0 and 94 years with a mean age of $44 \pm 10$ years. The male to female ratio seen in this study is $1.4: 1$ and the predominant age group is 31-40 years old age group. This gender ratio is similar to that of Nwafor et al. which was 1.4:1 in their study on natural causes of deaths in Benin but lower than that of Ugiagbe and

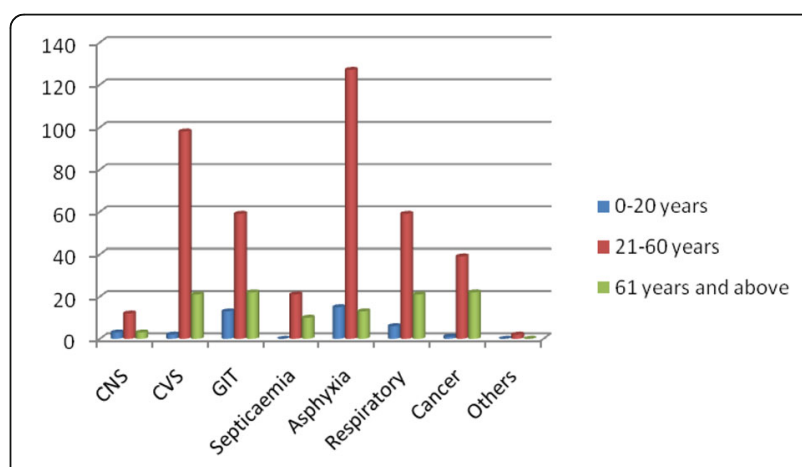

Fig. 1 Bar Chart showing the relative causes of Death with classified age groups. Shows that most death occurred in the 21-60 years age group. Cancer related deaths were very few in the younger age group which also showed no CVS and Septicaemia related deaths. Cardiovascular system related deaths with haemorrhage as the most common cause was majorly seen in the 21-60 years age group which coincided with the reproductive age group of women 
Ugiagbe which showed a ratio of $1.7: 1$ in their study on causes of sudden natural deaths (Nwafor et al. 2014; Ugiagbe and Ugiagbe 2012). The age range is also similar to that of Ugiagbe and Ugiagbe which was 19-105 years with a mean age of $51 \pm 17$ years (Ugiagbe and Ugiagbe 2012). The modal age in this study (31-40 years) is similar to that by Ambade et al. a study on decomposed bodies which was also 31-40 years but with a much higher male to female ratio of 3.9:1 (Ambade et al. 2011). This age group is however lower than that of the Benin studies which was 40-49 years but similar to Nwafor et al. study which was 25-44 years (Nwafor et al. 2014). This age group falls into the active work force age group of any nation and will have a great economic effect on such nation. There was male preponderance in all age groups except in the 3rd decade of life where the female gender predominated, the child bearing age group of women. This is believed to be as a result of the additional high maternal mortality rate seen in our environment (Hogan et al. 2010).

The classes of primary causes of deaths in this study showed, cardiovascular system causes was the most common (25.5\%) followed by asphyxia related causes were the most common (23.0\%), GIT (16.5\%), respiratory system (15.1\%), and cancer (10.9\%). Akinwusi et al. in their study on causes of sudden death in Ogbomosho, found a pattern of sudden death with respiratory disease (20.7\%), pulmonary thromboembolism (10.4\%), central nervous system disease $(13.8 \%)$, gastrointestinal disorders $(13.8 \%)$, severe chemical/drug poisoning (13.8\%), and combined cardiovascular and central nervous system disease (13.8\%) (Akinwusi et al. 2013). Ugiagbe and Ugiagbe in their study in Benin presented a pattern of death with immune/infectious diseases (mainly AIDS), gastrointestinal/hepatic lesions and respiratory diseases were seen in $15.2,14.1$ and $12.5 \%$ of cases respectively and showed SUNDs due to malignant neoplasms were not a common finding as they occurred in $5.1 \%$ of cases (Ugiagbe and Ugiagbe 2012). Nwafor et al. also showed gastrointestinal/hepatic diseases, $15.1 \%$; respiratory system diseases, $13.8 \%$; genitourinary system diseases, $10.1 \%$; immune/infectious diseases, $9.9 \%$ and endocrine/metabolic diseases, $7.7 \%$ as causes of sudden natural death (Nwafor et al. 2014). The pattern of rates of respiratory and GIT causes of sudden deaths is similar to that seen in our study on BID. The difference is that asphyxia deaths were not included in the SUNDs which was a common cause of death in our BID study.

In asphyxia related deaths, drowning and aspiration of gastric content accounted for most of the asphyxial deaths. Amdabe et al. in their study on autopsy on decomposed bodies in India found out that drowning (35.6\%) was the commonest cause of death in decomposed bodies (Ambade et al. 2011). The death from asphyxia were however seen more in the younger age group and this is consistent with other studies worldwide which showed asphyxia related BID occurred in the younger age group age range $0-78$ years (mean age of $37 \pm 10$ years). Bronchial asthma as well as aspiration of gastric contents, a purely medical emergency, are equally major causes of asphyxia deaths and if presented early can be managed properly and effectively. This brings to fore the need to improve the general awareness and proper knowledge of first aid management to the public. These major causes of asphyxia deaths, aspiration of gastric contents, drowning and strangulations are highly avoidable if proper precautionary measures are taken at home and at our recreational arenas.

Ventricular fibrillation following electrocution was a common cause of cardiovascular related deaths. A study by Mukherjee et al. on fatal electrocution cases in India showed the age range in their study was 2-67 years and majority of the victims (79.25\%) were males belonging to the age group of 11-30 years (Mukherjee et al. 2015). They opined that their study suggest that majority of the victims died in nondomestic environment in the rural region, most commonly in the farm which reflects the necessity of educating the farmers regarding proper use and precautions to be taken while handling electrically powered equipments (Mukherjee et al. 2015).

Other causes of deaths in the respiratory system are largely under the thromboembolic phenomenon, infections (which included miliary tuberculosis bronchopneumonia, lobar pneumonia) and respiratory failure. The high rate of death from pulmonary tuberculosis and pneumonia calls for better management of infectious conditions before they present as BID. Di Miao and Di Miao in their preview of cases of deceased who had natural deaths in USA; a developed country, showed that diseases of the central nervous and respiratory systems accounted for 8.7 and $8.6 \%$, respectively, of the natural deaths with seizure disorders and pneumonia were the main causes of death in these organ systems (Di Maio and Di Maio 1991). The high rate of infection and especially pulmonary tuberculosis brings to fore the urgent need for the government to intensify the prompt treatment of pulmonary tuberculosis among the infected. Moreover, medical management of chronic diseases must include early immobilisation of patients and the use of antithrombotic drugs to reduce the spate of deep venous thrombosis and pulmonary thromboembolism cannot be over emphasised.

GIT causes of deaths are majorly a sequel to loss of large quantity of fluid causing severe dehydration and hypovolaemic shock which together accounted for $55.3 \%$ of death as a result of GIT causes. The age range of patients here is $0-94$ years with a mean age of $45 \pm 22$ years. Also infection of the GIT causing peritonitis is another substantial cause of BIDs. These deaths were caused by gastroenteritis 
which can be properly treated if management is commenced in time. There are high levels of peptic ulcer disease with perforations which usually cause chemical peritonitis.

Haemorrhagic causes are mostly seen in the female gender and are mainly related to maternal mortality deaths. This included ruptured tubal gestation, retained placenta, retained products of conception, ruptured uterus and cervical laceration accounting for 65\% (33 out of 51) of all death due to haemorrhage. Kumar and Agrawal in their study on BID of maternal deaths showed most common cause of death was postpartum hemorrhage (54.68\%) followed by hypertension (15.62\%) and the most common cause of delay was delay in getting adequate treatment (56.25\%) (Kumar and Agrawal 2016). A similar study by Orji et al. at Ile Ife, they found causes of death include eclampsia, ruptured uterus, severe postpartum haemorrhage, severe antepartum haemorrhage, sickle cell anaemia with crises and road traffic accidents (Orji et al. 2002). Orji et al. concluded that prevention of 'brought in' maternal deaths requires social transformation, overhauling the healthcare delivery services and improving the socioeconomic status of the population (Orji et al. 2002). The high rate of maternal BID seen in this study reflects the high maternal mortality seen in our environment (Hogan et al. 2010). In all of these, these causes are highly preventable and can be managed properly (Hogan et al. 2010).

For the younger age group, $0-20$ years, asphyxia was the leading cause of BID, which is followed by GIT causes which are mostly gastroenteritis. This finding is in line with that of Akhiwu et al. in their study on SUND in which death during childhood was caused by respiratory diseases, gastrointestinal diseases, malaria, and central nervous system diseases (Akhiwu et al. 2013). It is worthy of note that there were no BID deaths as a result of cancer and CVS related deaths in this age group. This is expected since cardiovascular problems do not usually start in this age group. Furthermore, incidence of cancer in this age group is relatively low apart from the childhood cancers.

Among the middle ages group, 21-60 years, asphyxia deaths also predominated which was followed by cardiovascular, respiratory and then GIT causes. It should be emphasised that the relative percentage of haemorrhage related deaths doubled in this age group compared to the childhood and older age group because of the high maternal mortality related deaths seen in the female gender in this group. There was also relatively higher cancer related deaths in the over 60 years age group.

\section{Conclusion}

Cardiovascular system related death was the most common cause of BID with thromboembolism and haemorrhage as major secondary causes. Asphyxia related death was the second most common cause of brought in death with drowning and aspiration of gastric 'content as a major secondary cause. Tuberculosis was the commonest cause of death in the respiratory system. BID are seen more in male than the female gender and the highest age presentation for females was the 2nd and 3rd decade of life, the active child bearing age of women. Most cases of BID can be effectively treated if they present early in the hospital. There is need for the government to increase awareness and health seeking behaviour as well as proper first aid management among the populace.

\section{Abbreviation \\ AIDS: Acquired immune deficiency Syndrome; BID: Brought in Dead; CNS: Central Nervous System; CVS: Cardiovascular system; \\ GIT: Gastrointestinal tract; HHD: Hypertensive heart disease; SUND: Sudden unexpected death; WHO: World Health Organisation}

\section{Acknowledgements}

Not applicable

Funding

None declared

Availability of data and materials

The dataset supporting the conclusions of this article is included within the article.

\section{Authors' contributions}

FFA was involved in the conceptualization, literature search, data analysis and discussion of the study. SSS was involved in the literature search, data analysis and discussion. SDA was involved in the literature search and discussion; EFE was involved in the literature search and discussion: OFI was involved in the collection of data, analysis and literature search. WKO was involved in the literature search, data analysis and discussion. All authors read and approved the final copy.

\section{Authors' information}

FFA is an Associate Professor and a Consultant Pathologist; SSS is a Senior Lecturer and Consultant Pathologist; SDA is a Lecturer 1 with Lagos State College of Medicine, and EFE is a Consultant Pathologist; all in the

Department of Pathology and Forensic Medicine, LASUTH, Ikeja. OFI is a Senior Registrar in the Department of Pathology and Forensic Medicine, LASUTH, Ikeja and WKO is a Consultant Public Health Physician in the Department of Community Health and Primary Health Care, Lagos State University Teaching Hospital, Ikeja, Lagos, Nigeria.

\section{Ethics approval and consent to participate}

We obtained Health Research and Ethics Committee of Lagos State University Teaching Hospital (NHREC04/04/2008) consent to use the patients' data and publish the manuscript.

\section{Consent for publication}

Not applicable.

\section{Competing interests}

The authors declare that they have no competing interests.

\section{Publisher's Note}

Springer Nature remains neutral with regard to jurisdictional claims in published maps and institutional affiliations.

\section{Author details}

'Department of Pathology and Forensic Medicine, Lagos State University Teaching Hospital, Ikeja, Lagos, Nigeria. ${ }^{2}$ Department of Pathology and Forensic Medicine, Lagos State University College of Medicine, Ikeja, Lagos, Nigeria. ${ }^{3}$ Department of Community Health and Primary Health Care, Lagos State University Teaching Hospital, Ikeja, Lagos, Nigeria. 
Received: 2 May 2017 Accepted: 22 February 2018

Published online: 01 March 2018

\section{References}

Adesunkanmi AR, Akinkuolie AA, Badmus OS (2002) A five year analysis of death in an accident and emergency room in a semi-urban hospital. West Afr J Med 21:99-104

Akhiwu WO, Nwafor CC, Igbe AP (2013) A 20 year retrospective analysis of medicolegal deaths in a tertiary hospital setting in Nigeria. Niger J Clin Pract 16:535-539

Akinwusi PO, Komolafe AO, Olayemi OO, Adeomi AA (2013) Pattern of sudden death at Ladoke Akintola University of Technology Teaching Hospital, Osogbo, south West Nigeria. Vasc Health Risk Manag 9:333-339

Ambade VN, Keoliya AN, Deokar RB, Dixit PG (2011) Decomposed bodies still an unrewarding autopsy? J Forensic Legal Med 18:101-106

Di Maio VJ, Di Maio DJ (1991) Natural death as viewed by the medical examiner: a review of 1000 consecutive autopsies of individuals dying of natural disease. J Forensic Sci 36:17-24

Ekere AU, Yellowe BE, Umune S (2005) Mortality pattern in the accident and emergency department of an urban hospital in Nigeria. Niger J Clin Pract 8:14-18

Gülmen MK, Meral D (2009) Ani kardiyak ölümler. Klinik Gelişim 22:56-59

Hogan MC, Foreman KJ, Naghavi M, Ahn SY, Wang M et al (2010) Maternal mortality for 181 countries, 1980-2008: a systematic analysis of progress towards millennium development goal. Lancet 375:1609-1623

Jafarery SN, Korejo R (1995) Social and cultural factors leading to mothers being brought dead to hospital. Int J Gynecol Obstet 50:597-S99

Kumar A, Agrawal N (2016) Brought in dead: an avoidable delay in maternal deaths. J Obstet Gynaecol India 66(suppl 1):60-66

Lagos State Coroners law Lagos state coroner law 2007. Available from: http://www.lagoshouseofassembly.gov.ng/?in=\&up=bill. Accessed 21 Dec 2017.

Mukherjee B, Farooqui JM, Farooqui AA (2015) Retrospective study of fatal electrocution in a rural region of western Maharashtra, India. J Forensic Legal Med 32:1-3

Nwafor CC, Igbe AP, Akhiwu WO (2014) Study of natural causes of death in medicolegal autopsies seen in University of Benin Teaching Hospital. Niger Postgrad Med J 21:305-310

Orji EO, Ogunlola 1O, Onwudiegwu U (2002) Brought in maternal deaths in southwest Nigeria. J Obstet Gynaecol 22:385-388

Ugiagbe EE, Ugiagbe RA (2012) Causes of sudden natural death: a medicolegal autopsy study of medical cases in an African referral Centre. East Afr Med J 89:332-338

\section{Submit your manuscript to a SpringerOpen ${ }^{\circ}$ journal and benefit from:}

- Convenient online submission

- Rigorous peer review

- Open access: articles freely available online

- High visibility within the field

Retaining the copyright to your article

Submit your next manuscript at $>$ springeropen.com 